\title{
Pleural effusion in relapsing pancreatitis
}

\author{
J. J. Manns* \\ Regional Thoracic Unit, \\ Sully Hospital, Glamorgan
}

\begin{abstract}
Summary
A case of relapsing pancreatitis complicated by massive pleural effusion is described and the difficulties in confirming the diagnosis are illustrated. The possibility of a pancreatic encephalopathy is also considered.
\end{abstract}

A small coincident pleural effusion occurs commonly in acute pancreatitis (Coffey, 1952; Stein et al. 1959; Roseman, Kowlessar \& Sleisenger 1960; Fishbein, Murphy \& Wilder 1962; Kaye, 1968; Miridjanian et al., 1969.) Massive pleural effusions are rare and frequently cause diagnostic confusion in acute and chronic pancreatitis (Roseman et al., 1960, Kaye, 1968; Miridjanian et al., 1969). A case of relapsing pancreatitis, complicated by a massive pleural effusion is described.

\section{Case report}

The patient, a male aged 28 years, had first presented 3 years earlier with acute abdominal pain, nausea and vomiting.

On examination he was anxious and afebrile, there was a sinus tachycardia and he was normotensive. The abdomen was rigid with normal bowel sounds and abdominal X-ray showed no evidence of a perforated viscus. Serum amylase 266 Somogyi units/ml, (normal 0-160 units $/ \mathrm{ml}$ ). He was treated conservatively and $48 \mathrm{hr}$ later became febrile with confusion, agitation and visual hallucinations. A history of heavy drinking was obtained and he was considered to have delirium tremens. 8 months later he had a similar episode. At this time there was some evidence of a personality disorder. Psychometric assessment showed a low-average IQ and electroencephalography showed dysrhythmia in the right temporal lobe. He was then diagnosed as having schizophrenia, or temporal lobe epilepsy with an abdominal aura. 5 months later, following further episodes of abdominal pain associated with hallucinations he was noted to have a serum amylase of 300 Somogyi units $/ 100 \mathrm{ml}$ and the diagnosis of relapsing pancreatitis was made. The patient

* Present address: Department of Medicine, Dundee Royal Infirmary. remained reasonably well for 2 years and then presented with an acute episode of right pleuritic pain and dyspnoea. Examination suggested a large pleural effusion with mediastinal compression and this was confirmed by chest X-ray. Pleural aspiration produced a sterile blood stained, lymphocytic exudate. Mantoux $(1: 1000)$ was negative and there was no clinical or radiological evidence of trauma. The patient was then transferred to the Regional Thoracic Unit for further investigation.

On admission it was established that the hallucinatory episode always coincided with episodes of abdominal pain and that the patient had consumed an average of sixty-five pints of beer per week for the past 10 years.

On examination he was thin, pale and afebrile, with early finger clubbing, The right hemithorax was immobile and dull to percussion, with absent breath sounds and displacement of the trachea and apex beat to the left. There was epigastric tenderness and normal bowel sounds. There was no psychiatric abnormality and no focal neurological signs. Shortly after admission the patient became febrile, developed acute abdominal pain with vomiting and had auditory and visual hallucinations. Examination showed generalized abdominal rigidity but normal bowel sounds. There were no abnormal neurological signs. This episode settled spontaneously within $24 \mathrm{hr}$.

Investigations. $\mathrm{Hb} 11.25 \mathrm{~g} / 100 \mathrm{ml}$, WBC 6000 cells/ $\mathrm{mm}^{3}$, ESR $124 \mathrm{~mm}$ Westergren, blood urea normal, plasma electrolytes normal, serum proteins $6.6 \mathrm{~g} / 100 \mathrm{ml}$, albumin $3.1 \mathrm{~g} / 100 \mathrm{ml}$, bilirubin normal, alkaline phosphatase $30 \mathrm{KA}$ units, SGPT,44 SF units $/ 100 \mathrm{ml}$, SGOT $53 \mathrm{SF}$ units $/ 100 \mathrm{ml}$ (normal 0-40 SF units $/ 100 \mathrm{ml}$ ), serum amylase 325 Somogyi units $/ 100 \mathrm{ml}$. Cholecystogram showed air in the gall bladder and common bile duct, barium meal normal, i.v. cholangiogram normal, liver scan normal, percutaneous liver biopsy normal. ${ }^{75} \mathrm{Se}$ pancreatic scan showed absent uptake in the head of the pancreas suggesting a pseudo-pancreatic cyst.

It was considered that the diagnosis in this case was relapsing pancreatitis complicated by a pancreatic pleural effusion. The diagnosis was confirmed 
at pleural aspiration, the amylase level of the pleural fluid being 40,000 Somogyi units $/ 100 \mathrm{ml}$.

In spite of repeated aspiration the effusion did not resolve and right pleurectomy was done. At operation there was a suradiaphragmatic sterile empyema communicating with an interlobar loculus.

Since operation the patient had had a normal chest X-ray. He has avoided alcohol and has been free of abdominal pain but continues to have episodes of aggressiveness and paranoia requiring admission to a psychiatric unit.

\section{Discussion}

Relapsing pancreatitis is an uncommon condition usually diagnosed by recurrent acute episodes of pancreatitis. Our patient had several acute abdominal episodes resembling acute pancreatitis and although the serum amylase measurements at these times were not markedly raised, peptic ulceration and gall bladder disease were excluded as possible causes of diagnostic confusion. In addition a ${ }^{75} \mathrm{Se}$ pancreatic scan suggested abnormality. Unfortunately pancreatic stimulation tests were not available at the time of diagnosis. Thus, as is often necessary, a clinical diagnosis was made (Smith, 1957).

Massive pleural effusion can complicate acute or chronic pancreatitis. The pleural fluid can be blood stained or serous and, unless the amylase content of the pleural fluid is estimated, can cause considerable diagnostic confusion (Roseman et al., 1960; Kaye, 1968; Miridjanian et al., 1969).

Elevation of the pleural fluid amylase can occur in a variety of conditions, e.g. with pneumonia or tuberculosis and particularly in neoplastic disease including bronchial carcinoma, retroperitoneal tumours and metastases involving the thoracic duct (Claus \& Wilson, 1958; Ende, 1960), but a level of many thousands of units as seen in this patient is considered to be diagnostic of pancreatitis (Werner, 1942; Hammarsten, Honska \& Limes, 1959; Roseman et al., 1960; Kaye, 1968).

Pancreatic pleural effusions can resolve spontaneously or can recur in the other hemithorax (Miridjanian et al., 1969) and can be complicated by empyema, as in our patient, or broncho-pleural fistula (Kaye, 1968). Pleurectomy would appear to be an effective treatment in the difficult case.

The pathogenesis of the pleural effusion is unknown, the evidence for the various theories have been well reviewed recently (Kaye, 1968).

Another perplexing aspect of this case is the psychiatric disturbance. Pancreatic encephalopathy has been described in acute pancreatitis (Rothermich \& von Haam, 1941; Sharf \& Bental, 1971). The clinical picture is of acute delirium with diffuse neurological and electroencephalographic signs, commencing 2-5 days after an episode of acute pancreatitis. This would appear to be a more severe and prolonged neurological disturbance than we have witnessed. Our patient continues to have episodic psychosis in the absence of further attacks of pancreatitis and it is presumed that we have been witnessing acute schizophrenic reactions as a response to physical stress (Henderson \& Batchelor, 1969).

\section{Acknowledgments}

I am grateful to the late Dr L. R. West and Dr H. L. English for their permission to publish this case report and to Dr H. M. Foreman and Dr R. M. E. Seal for their helpful advice.

\section{References}

Claus, R.H. \& Wilson, D.W. (1958) Pancreatic pseudocyst of the mediastinum. Journal of Thoracic Surgery, 35, 795.

CofFeY, R.J. (1952) Unusual features of acute pancreatic disease. Annals of Surgery, 135, 715.

ENDE, N. (1960) Studies of amylase activity in pleural effusions and ascites. Cancer, 13, 283.

Fishbein, R., MurPhy, G.P., \& Wilder, R.J. (1962) The Pleuropulmonary complications of pancreatitis. Disease of the Chest, 41, 392.

Hammarsten, J.F., Honska, W.L. \& Limes, B.J. (1959) Pleural fluid amylase in pancreatic and other diseases American Review of Tuberculosis and Pulmonary Diseases, $79,606$.

Henderson, D. \& Batchelor, I.R.C. (1969) Henderson and Gillespie's Textbook of Psychiatry, p. 255, Oxford Medical Publications, Oxford.

KAYE, M.D. (1968) Pleuropulmonary complications of pancreatitis. Thorax, 23, 297.

Miridjanian, A., Ambruoso, V.N., Derby, B.D. \& Tice, D.A. (1969) Massive bilateral haemorrhagic pleural effusions in chronic relapsing pancreatitis. Archives of Surgery, 98, 62.

Roseman, D.M., Kowlessar, O.D., \& Sleisenger, M.H. (1960) Pulmonary manifestations of pancreatitis. New England Journal of Medicine, 263, 294.

Rothermich, O.N. \& voN HAAM, E. (1941) Pancreatic encephalopathy. Journal of Clinical Endocrinology, 1, 872.

Sharf, B. \& Bental, E. (1971) Pancreatic encephalopathy. Journal of Neurology, Neurosurgery and Psychiatry, 34, 357.

SMITH, R. (1957) In: Discussions on diagnostic features of some pancreatic diseases. Proceedings of the Royal Society of Medicine, 50, 639.

Stein, G.N., Kalser, M.H., Sarian, N.N. \& Finkelstein, A. (1959) An evaluation of the roentgen changes in acute pancreatitis: Correlation with clinical findings. Gastroenterology, 36, 354.

Werner, H. (1942) Pankreatogene pleuritis. Zentralblatt fur innere Medizin, 63, 577. 